\title{
3 Research Square

\section{Factors Related to Survival in Intensive Care Unit Patients with Covid-19: A study from a Single Center in Brazil.}

\section{Rodrigo Sardenberg}

Centro Internacional de Pesquisa do Hospital Alemão Oswaldo Cruz; Center of Research at Union of Great Lakes University https://orcid.org/0000-0002-6010-1829

Gabriel Antonio Roberto ( $\sim$ contatogabrielroberto@gmail.com )

Centro Internacional de Pesquisa do Hospital Alemão Oswaldo Cruz https://orcid.org/0000-0001-98149038

\section{Catarina Marchon Silva}

USCS: Universidade Municipal de Sao Caetano do Sul

Andrea Santos Galvão

Hospital Alemão Oswaldo Cruz: Hospital Alemao Oswaldo Cruz

\section{Daniela Jesus Meireles Ribeiro Pinho}

Hospital Alemão Oswaldo Cruz

\section{Tabatta Zambotto Sachelli}

Hospital Alemão Oswaldo Cruz: Hospital Alemao Oswaldo Cruz

Gabriela Bezerra Freitas Diniz

Hospital Alemão Oswaldo Cruz

\section{Research}

Keywords: COVID-19, coronavirus, ICU, comorbidities, pandemics.

Posted Date: September 20th, 2021

DOI: https://doi.org/10.21203/rs.3.rs-892542/v1

License: (c) (i) This work is licensed under a Creative Commons Attribution 4.0 International License. Read Full License 


\section{Abstract}

Introduction: The aim of this study is to the present an original research which describes the outcome in 268 ICU consecutive patients in a single center, as well analyzing the effects of viral infection on preexisting medical conditions such as hypertension, diabetes, obesity, chronic obstructive pulmonary disease, and how these factors affected survival and hospital stay.

Material and methods: We retrospectively analyzed patients included in this study who were admitted to ICU between March $18^{\text {th }} 2020$ until August $30^{\text {th }}$ 2020. All patients were analyzed under the same protocol at Hospital Alemão Oswaldo Cruz, São Paulo, Brazil. Several factors were considered, such as: age, gender, symptoms before hospitalization, comorbidities, vasopressors use, radiological findings and use of high flow nasal catheter. The results were presented using the hazard ratio and its respective $95 \%$ confidence intervals. For statistical inferences, $p<0.05$ was adopted for all analysis.

Results: The median age was 72 years, 64,2 years (53-74) for patients who were discharged, and 79.9 years $(71.4-88.4)$ for those deceased $(p<0.001)$. The most common comorbidities associated were: systemic arterial hypertension, diabetes, thyroid disease, cardiovascular and kidney disease. The univariate analysis showed the following factors as predictors of survival: myalgia $(p=0.001)$, cerebrovascular disease $(p=0.002)$, COPD $(p=0.003)$, dementia $(p=0.000)$, the need for mechanical ventilation $(p=0.000)$, dialysis $(0.000)$, vasopressors use (0.000), SAPS3 $(0.000)$, lymphopenia $(p=0.004)$, elevated $D$-dimer $(P=0.011)$, time in ICU before tracheostomy $(p=0.002)$, and performing a tracheostomy $(p=0.000)$. The independent predictors of mortality were: advanced age $(p=0.003)$; the non-use of vasopressor in the ICU was protective factor ( $p=0.001)$; tracheostomy performed in ICU was a mortality predictor $(\mathrm{p}=0.002)$.

Discussion: COVID-19 affects more older adults and there is also a high fatality rate in this subset of patients. Acute respiratory distress syndrome (ARDS) is the primary cause of death in and around $<5 \%$ of patients were reported as experiencing bacterial/fungal coinfection at admission. Our findings support the observations of earlier studies, which found a high percentage of hospitalized patients of advanced age with preexisting conditions, hypertension being the most common.

Conclusion: In our analysis, age, the need for vasopressors medications patients who underwent tracheostomy and underlying comorbidities, such as systemic coronary disease, heart failure, neoplasia, COPD, were found to be significantly associated with COVID-19 severity.

\section{Introduction}

In late December 2019, few cases of serious illness causing pneumonia and death were first reported in Wuhan, China. Soon after, the number of cases raised dramatically, spreading across China and then worldwide. 
The primary cluster of patients was found to be connected with the Huanan South China Seafood Market in Wuhan. Coronavirus belong to the family Coronaviridae (subfamily Coronavirinae), the members of which infect a broad range of hosts, producing symptoms and diseases ranging from the common cold to severe and ultimately fatal illnesses, such as SARS and MERS ${ }^{1,5}$. Analysis of the viral genome has revealed that the new coronavirus is phylogenetically close to severe acute respiratory syndrome coronavirus (SARS-CoV), the causative agent of a viral outbreak in $2002^{5}$.

The World Health Organization (WHO) announced the official name of the disease as "coronavirus disease 2019 (COVID-19)" and now publicly refers to the virus as "the COVID-19 virus" (formerly known as "2019-nCoV") ${ }^{1}$. The consequences for human health, the global economy, and normal functioning of society have been unprecedented ${ }^{2}$.

The virus causes infection in any age group, although severe disease is more common in older adults ${ }^{2}$. Patients with COVID-19 can be symptomatic or asymptomatic. According to most reports, mild symptoms occurred in about $81 \%$ of patients, include cough, sore throat, fever, myalgia, and moderate pneumonia 2,4 .

As of 8 August 2021, there was a total of 201.941 .078 confirmed cases globally. Of 192 countries registered cases that reached an outcome, 4.282 .732 resulted in mortality ${ }^{3}$. In Brazil, there were 31.895.385 COVID-19 cases and 561.762 deaths, with a $2.8 \%$ lethality rate. In São Paulo - the epicenter of the disease in Brazil - there are 4.113.741 confirmed cases and 140.677 deaths, with a $3.9 \%$ lethality rate $^{4}$.

The disease can lead to organ dysfunction-shock, severe acute respiratory syndrome (SARS), acute cardiac injury, and acute kidney injury (AKI)-and death ${ }^{2}$. While most COVID-19 patients will not require supportive care, $10-15 \%$ of patients develop acute respiratory distress that require invasive ventilatory support ${ }^{1}$. Patients with serious disease showed symptoms of severe pneumonia, dyspnea, and very low blood oxygen saturation ( $\leq 93 \%$ ), which was observed in about $14 \%$ of cases 7,8 .

Critical symptoms occurred in about $5 \%$ of cases and included respiratory failure, multiorgan failure, and septic shock. Mild infections were observed to clear up in a week, whereas severe cases experienced acute respiratory failure, even leading to sepsis and death. Most fatalities were reported in middleaged/elderly populations with preexisting conditions, including diabetes, heart and kidney diseases, chronic obstructive pulmonary disease, cancer, and immune diseases ${ }^{7}$.

The mortality rates are approximately $2 \%-3 \%$. Older age, presence of comorbidities such as hypertension, diabetes, cardiovascular disease, chronic lung disease, cancer, higher d-dimer and C-reactive protein, and lower lymphocyte levels are associated with higher mortality 7,8 . Therefore, there is an urgent need for effective and specific antiviral treatment. Currently, supportive care measures such as ventilation oxygenation and fluid management remain the standard of care. Several clinical trials are currently trying 
to identify the most potent drug or combination against the disease and it is strongly recommended to enroll patients into ongoing trials ${ }^{3,6}$.

Mechanical ventilation (MV) for patients infected with the severe acute respiratory syndrome coronavirus 2 (SARS-CoV-2) is associated with a prolonged airway intubation and high worldwide mortality of at least $50-67 \%{ }^{3}$.

The development cycle of a vaccine production against SARS-CoV-2 moved remarkably fast given the major pandemic issue that has emerged and major international vaccine funding agencies are supporting the multitude of innovative ongoing efforts. Nowadays, vaccination is being applied around the world with optimistic results, reducing the number of infected people, hospitalizations, and deaths ${ }^{6}$.

In this light, the present an original research which describes the outcome in $268 \mathrm{ICU}$ patients in a single center, as well analyzing the effects of viral infection on preexisting medical conditions such as hypertension, diabetes, cardiovascular diseases, obesity, chronic obstructive pulmonary disease, kidney disease, cancer, and how these factors affected survival and hospital stay.

\section{Material And Methods}

We retrospectively analyzed patients included in this study $(n=268)$, who were admitted to ICU between March 18th 2020 until August 30th 2020. All patients were analyzed under the same protocol at Hospital Alemão Oswaldo Cruz, São Paulo, Brazil.

The patients had COVID-19 infection documented by nasal pharyngeal swab for reverse transcriptase polymerase chain reaction (rt-PCR) assay, and developed severe respiratory failure requiring admission to ICU. Data were collected following a medical record review of each patient chart. The institutional review board approved this study (\#4.849.542).

Patients with the following characteristics were considered eligible for analysis: 1) Covid-19 confirmed by test, 2) admission to ICU.

Several COVID-19 related factors were considered, including: age, gender, symptoms before hospitalization, comorbidities, vasopressors use, radiological findings, use of high flow nasal catheter, prone position, ECMO, tracheostomy and blood tests.

In addition, we collected variables such as: type and duration of symptoms when entering ICU, FIO2 and $\mathrm{PaO} 2 / \mathrm{FiO} 2$ relation, and total time of hospitalization.

The majority of the patients underwent chest CT scan prior ICU, in order to evaluate the extent of lung lesions by SARS-Cov-2, which was divided into four degrees: $<25 \%, 25-50 \%, 50-75 \%$ and $>75 \%$.

\section{Statistical Analyses}


For database preparation and descriptive analysis, the Statistical Package for the Social Sciences software (SPSS Inc., Chicago, IL, USA), version 17.0 for Windows, was used. The results were generated by means of tables and graphs. Categorical variables expressed in frequencies and percentages - $\mathrm{n}(\%)$. Continuous variables with normal distribution were expressed as means and standard deviations; and those with non-normal distribution, in median and interquartile range. The normality of the numerical variables was verified through descriptive statistics, graphical analysis and the Kolmogoronov Sminov test.

In the comparison between groups (hospital discharge vs. death) for the numerical variables, the independent $t$ test was used, when the variables had a normal distribution and the Mann-Whitney test for those with an asymmetric distribution. In the comparison between groups and categorical variables, the chi-square $\left(\mathrm{X}^{2}\right)$ test was used, when the distribution had an $\mathrm{n}$ in each category less than five individuals, Fischer's exact test was used.

The COX regression model was used to evaluate the predictive variables for mortality in patients with COVID-19. After univariate analysis, independent variables were inserted into the COX model, remaining in the model if they remained significant $(p<0.05)$. The manual procedure for inserting and removing variables was adopted. The results were presented using the hazard ratio and its respective $95 \%$ confidence intervals. The Kaplan- Mayer was used for patients' survival curves. For statistical inferences, $p<0.05$ was adopted for all analysis.

\section{Results}

Two hundred patients (74.6\%) were discharged from hospital (139 male and 34 female), and 68 patients (44 male and 24 female) were not discharged or died (25.4\%).

There is a higher incidence from male in both groups. The longer the hospital stay, the greater the chance of death (Figs. 1 and 2).

The mean time duration of symptoms before hospital admission was 5.5 days, seven days (4-9) for discharged patients and four days $(2-6.75)$ for the patients not discharged from hospital $(p<0,001)$. The last group mentioned had a longer hospital stay, showing a faster unfavorable outcome for these patients. We noticed the shorter symptoms duration, the faster the progression to severe presentation.

The most common comorbidities associated were: systemic arterial hypertension- $S A H(n=144)$, diabetes $(n=80)$, thyroid disease $(n=53)$, cardiovascular disease $(n=52)$, kidney disease $(n=33)$, cerebrovascular disease or previous stroke $(n=12)$, obesity $(n=60)$, neoplasia $(n=35)$, COPD $(n=15)$ and dementia $(n=22)$, as shown on (Table 1$)$. 
Table 1

- Comparation of clinical characteristics between groups

\section{Discharge from the Hospital}

$p=$
value

\begin{tabular}{lll} 
Variables & Yes $(\mathbf{n}=\mathbf{2 0 0})$ & No $(\mathbf{n}=\mathbf{6 8})$ \\
\hline Age M(IIQ) & $64,2(53-74)$ & $79,9(71,4-8$ \\
\hline Symptoms of pre-hospitalization time M(IIQ) & $7(4-9)$ & $4(2-6,75)$ \\
\hline Sex & & \\
\hline Female & $64(32,0)$ & $24(35,3)$ \\
Male & $136(68,0)$ & $44(64,7)$
\end{tabular}

\section{Symptoms before admission}

\begin{tabular}{llll} 
Fever & $137(68,5)$ & $42(61,8)$ & $0,308^{\star \star}$ \\
\hline Cough & $125(62,5)$ & $41(60,3)$ & $0,746^{\star \star}$ \\
\hline Dyspnea & $151(75,5)$ & $55(80,9)$ & $0,363^{\star \star}$ \\
\hline Diarrhea & $39(19,5)$ & $12(17,6)$ & $0,737^{\star \star}$ \\
\hline Abdominal pain, nausea or Vomiting & $40(20,0)$ & $7(10,3)$ & $0,069^{\star \star}$ \\
\hline Myalgia & $73(36,5)$ & $10(14,7)$ & $0,001^{\star \star}$ \\
\hline Ageusia or Anosmia & $21(10,5)$ & $2(2,9)$ & $0,055^{\star \star}$ \\
\hline Comorbidities & & & \\
\hline Thyroid disease & $37(18,5)$ & $16(23,5)$ & $0,368^{\star \star}$ \\
\hline Hypertension & $102(51,0)$ & $42(61,8)$ & $0,124^{\star \star}$ \\
\hline Diabetes & $57(28,5)$ & $23(33,8)$ & $0,407^{\star \star}$ \\
\hline Coronary insufficiency & $19(9,5)$ & $13(19,1)$ & $0,035^{\star \star}$ \\
\hline Cerebrovascular disease / or Previous stroke & $12(6,0)$ & $9(13,2)$ & $0,055^{\star \star}$ \\
\hline Cardiac insufficiency & $9(4,5)$ & $11(16,2)$ & $0,002^{\star \star}$ \\
\hline Smoking & $27(13,5)$ & $13(19,1)$ & $0,261^{\star \star}$ \\
\hline Obesity & $60(30,0)$ & $19(27,9)$ & $0,748^{\star \star}$ \\
\hline Neoplasia & $10(5,0)$ & $14(20,6)$ & $0,000^{\star \star}$ \\
\hline
\end{tabular}

$\mathrm{M}=$ Median; IIQ = Interval inter-quartil; $\mathrm{m}$ = mean; $\mathrm{DP}=$ standard deviation; * = Mann-whitney Test; * =qui-quadrado Test; ${ }^{\star \star \star}=\mathrm{T}$ independente Test; ${ }^{\mathrm{a}}=$ exact fischer Test; 


\begin{tabular}{|c|c|c|c|}
\hline \multirow[b]{2}{*}{ Variables } & \multicolumn{2}{|c|}{ Discharge from the Hospital } & \multirow{2}{*}{$\begin{array}{l}p= \\
\text { value }\end{array}$} \\
\hline & Yes $(n=200)$ & No $(n=68)$ & \\
\hline $\begin{array}{l}\text { Hematological neoplasia or Sd } \\
\text { Myelodysplasias }\end{array}$ & $8(4,0)$ & $3(4,4)$ & $0,882^{a}$ \\
\hline DOPC & $15(7,5)$ & $14(20,6)$ & $0,003^{\star *}$ \\
\hline Asthma & $7(3,5)$ & $2(2,9)$ & $0,825^{a}$ \\
\hline Dementia & $22(11,0)$ & $20(29,4)$ & $0,000 \star *$ \\
\hline Autoimmune Disease & $11(5,5)$ & $4(5,9)$ & $0,906^{a}$ \\
\hline HIV & $3(1,5)$ & 0 & $0,310^{a}$ \\
\hline Chronic Non-Dialectical Kidney Disease & $19(9,5)$ & $9(13,2)$ & 0,384 ** \\
\hline Chronic Dialytic Kidney Disease & $4(2,0)$ & $1(1,5)$ & $0,780^{a}$ \\
\hline Cirrhosis & $1(0,5)$ & $1(1,5)$ & $0,422^{a}$ \\
\hline Solid Organ Transplantation & $4(2,0)$ & $1(1,5)$ & $0,780^{a}$ \\
\hline \multicolumn{4}{|l|}{ Drugs } \\
\hline BRA/IECA & $63(31,5)$ & $24(35,3)$ & 0,564 *夫 \\
\hline $\begin{array}{l}\text { Use of systemic corticosteroids in the last } 14 \\
\text { days }\end{array}$ & $39(19,5)$ & $15(22,1)$ & $0,650^{\star \star}$ \\
\hline Chemotherapy & $8(4,0)$ & $6(8,8)$ & $0,123^{\star \star}$ \\
\hline Immunosuppressors & $7(3,5)$ & $2(2,9)$ & $0,825^{a}$ \\
\hline Mechanical Ventilation Invasive on Admission & $17(8,5)$ & $11(16,2)$ & 0,074 *夫 \\
\hline Vasopressor in ICU admission & $17(8,5)$ & $6(8,8)$ & 0,934 *夫 \\
\hline \multicolumn{4}{|l|}{ Admission Exams } \\
\hline Chest tomography & $191(95,5)$ & $65(95,6)$ & 0,976 ** \\
\hline Radiological infiltrate & & & 0,636 ** \\
\hline Hospitalization Time Pre-ICU admission & $1(0-3)$ & $1(0-4)$ & $0,470^{*}$ \\
\hline Without infiltration & $14(7,0)$ & $7(10,3)$ & \\
\hline$<25 \%$ & $36(18,0)$ & $16(23,5)$ & \\
\hline
\end{tabular}




\begin{tabular}{|c|c|c|c|}
\hline \multirow[b]{2}{*}{ Variables } & \multicolumn{2}{|c|}{ Discharge from the Hospital } & \multirow{2}{*}{$\begin{array}{l}p= \\
\text { value }\end{array}$} \\
\hline & Yes $(n=200)$ & No $(n=68)$ & \\
\hline $25-50 \%$ & $83(41,5)$ & $24(35,3)$ & \\
\hline $50-75 \%$ & $46(23,0)$ & $12(17,6)$ & \\
\hline$>75 \%$ & $7(3,5)$ & $2(2,9)$ & \\
\hline Not suggestive & $14(7,0)$ & $7(10,3)$ & \\
\hline \multicolumn{4}{|l|}{ Using in ICU time } \\
\hline Use of the prone position & $22(11,1)$ & $10(14,7)$ & $0,424^{* *}$ \\
\hline Extracorporeal circulation in use & $6(3,0)$ & $1(1,5)$ & $0,491^{\star *}$ \\
\hline oxygen therapy & & & $0,076 * *$ \\
\hline Invasive Ventilation & $75(37,5)$ & $49(72,1)$ & $0,000 * *$ \\
\hline Vasopressor in ICU & $68(34,0)$ & $53(77,9)$ & $0,000 * *$ \\
\hline Dialysis & $32(16,0)$ & $29(42,6)$ & $0,000 * *$ \\
\hline Antimicrobial & $176(88,0)$ & $65(95,0)$ & $0,073^{* *}$ \\
\hline Tracheostomy & $22(11,0)$ & $21(30,9)$ & $0,000 * *$ \\
\hline Time in ICU before tracheostomy M(IIQ) & $11,5(7-18)$ & $19(14,5-25,5)$ & $0,002^{*}$ \\
\hline Catheter Nasal (CN) & $138(69,0)$ & $36(52,9)$ & \\
\hline No using & $7(3,5)$ & $2(2,9)$ & \\
\hline High Flow NC & $10(5,0)$ & $4(5,9)$ & \\
\hline Mask ventilation & $45(22,5)$ & $26(38,2)$ & \\
\hline \multicolumn{4}{|l|}{ ICU admission parameters } \\
\hline SAPS3 M(IIQ) & $45(41-51,7)$ & $51(44,3-57,0)$ & $0,000 *$ \\
\hline Blood pressure $\mathrm{M}(\mathrm{IIQ})$ & $\begin{array}{l}120(110- \\
131,75)\end{array}$ & $118,5(103-141,5)$ & $0,600 *$ \\
\hline Breathing Frequency M(IIQ) & $22(19-26)$ & $22(19,3-26)$ & $0,770 *$ \\
\hline \multicolumn{4}{|l|}{ Hospital admission parameters } \\
\hline Saturation $02 \% \mathrm{M}(\mathrm{IIQ})$ & $94(92-96,8)$ & $94(90-96)$ & $0,270 *$ \\
\hline
\end{tabular}

$\mathrm{M}=$ Median; IIQ = Interval inter-quartil; $\mathrm{m}$ = mean; $\mathrm{DP}=$ standard deviation; * = Mann-whitney Test; ** =qui-quadrado Test; ${ }^{* \star *}=$ T independente Test; ${ }^{a}=$ exact fischer Test; 


\begin{tabular}{|c|c|c|c|}
\hline \multirow[b]{2}{*}{ Variables } & \multicolumn{2}{|c|}{ Discharge from the Hospital } & \multirow{2}{*}{$\begin{array}{l}p= \\
\text { value }\end{array}$} \\
\hline & Yes $(n=200)$ & No $(n=68)$ & \\
\hline Temperature ${ }^{\circ} \mathrm{C} \mathrm{m} \pm \mathrm{DP}$ & $36,7 \pm 0,9$ & $36,6 \pm 0,8$ & $0,491 * \star \star$ \\
\hline Relation P02/F102 M(IIQ) & $236(135-328)$ & $192(125-275)$ & $0,127 *$ \\
\hline Relation arterial gas $02 / \mathrm{Fi02} \mathrm{M}(\mathrm{IIQ})$ & $247(99-334)$ & $227(99-305)$ & $0,250^{*}$ \\
\hline Leukocytes $\times 10^{3} \mathrm{M}(\mathrm{IIQ})$ & $14(9,5-19,2)$ & $14,9(6,9-20,7)$ & $0,611^{*}$ \\
\hline CRP C-reactive protein M(IIQ) & $11(5,97-19,57)$ & $\begin{array}{l}11,38(6,31- \\
19,74)\end{array}$ & $0,700 *$ \\
\hline D-dímer M(IIQ) & $850(534-1566)$ & $1193(666-3511)$ & $0,011 *$ \\
\hline AST/ALT M(IIQ) & $33(23-47)$ & $29(20-53)$ & $0,198^{*}$ \\
\hline LDH Lactate dehydrogenase M(IIQ) & $615(481-776)$ & $657(545-841)$ & $0,338^{*}$ \\
\hline Creatinine $\mathrm{M}(\mathrm{IIQ})$ & $0,94(0,79-1,32)$ & $1,09(0,82-1,5)$ & $0,112^{*}$ \\
\hline Bilirubin $M(I I Q)$ & $0,39(0,27-0,56)$ & $0,35(0,26-0,48)$ & $0,171^{\star}$ \\
\hline \multicolumn{4}{|l|}{ Hospital total time analyses } \\
\hline Days on mechanical ventilation $\mathrm{M}(\mathrm{IIQ})$ & $12(7,5-16)$ & $15(4,5-26)$ & $0,325^{\star}$ \\
\hline Total time of hospitalization M(IIQ) & $17(10-31)$ & $18,5(10-37)$ & $0,592^{\star}$ \\
\hline 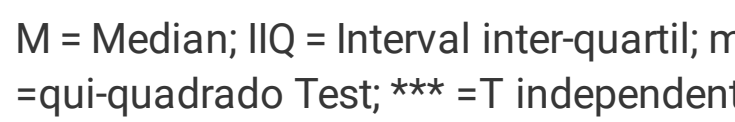 & $\begin{array}{l}P=\text { standard devia } \\
\text { xact fischer Test; }\end{array}$ & ; ${ }^{*}=$ Mann-whitr & Test; ** \\
\hline
\end{tabular}

One hundred and two patients used any kind of drug before admitted to ICU (Table 1), as follows: ACE inhibitors $(n=87)$, systemic corticosteroids $(n=54)$, chemotherapy $(n=14)$ and immunosuppressive drugs $(n=9)$.

The median age was 72 years, 64,2 years (53-74) for patients who were discharged, and 79.9 years (71.4-88.4) for those not discharged $(p<0.001)$. The group of patients who was not discharged from hospital was composed of the oldest ones (Table 1).

The most common symptoms before hospital admission were dyspnea $(n=206 / 78 \%)$, fever $(n=179$ / $65 \%)$, cough $(n=166 / 60 \%)$, diarrhea $(n=51 / 18.5 \%)$ and myalgia $(n=83 / 25.6 \%)$. Dyspnea was the most prevalent symptom, especially for those who were not discharged $(n=55 / 80.9 \%)$.

Regarding lung affection before ICU admission, 21 patients had no specific CT findings, 52 patients had less than $25-\%$ (20.7\%), 107 had $25-50 \%$ (38.4\%), 58 had $50-75 \%(20.3 \%)$ and nine (3.2\%) patients > 75\% of lobes involved by SARS-CoV-2. 
During ICU admission, the median SAPS (Simplified Acute Physiology Score) 3 was 45 (41-51.7) for the discharged patients and 51 (44.3-57) for the non- discharged ones; 174 patients (60.9\%) had oxygen additional through nasal catheter, 14 patients $(5,4 \%)$ needed high flow nasal catheter, $28(12.3 \%)$ patients required mechanical ventilation and 23 (8.6\%) needed vasopressors. The median $\mathrm{PaO} 2 / \mathrm{FiO} 2$ relation was 236 (135-328) for the group discharged from hospital and 192 (125-275) for the non-discharged patients.

During hospital stay, 32 patients (12.9\%) underwent prone position, 33 patients $(20.9 \%)$ underwent tracheostomy and seven (2.2\%) patients needed ECMO support.

The laboratory tests showed the following findings (median) during hospital admission: leukocytes 7.410 and 8.015, lymphocytes 910 and 700, and C-reactive protein 11 and 11.38, D-dimer 850 and 1.193, LDH (Lactate dehydrogenase) 615 and 657, creatinine 0.94 and 1.09, in the discharged and not discharged patients respectively.

The median days on mechanical ventilation was 12 (7.5-16), hospitalization total time of $17(10-31)$ and 18.5 (10-37), and ICU time before tracheostomy 11.5 (7-18) and 19 (14.5-25.5), for those discharged and not discharged groups.

We can conclude the following findings in Table 1 that:

- Older age in the group that was not hospital discharged had worse prognosisis;

- A shorter duration of symptoms pre-hospitalization in the deceased group;

- A greater incidence of myalgia in the group that was discharged from the hospital;

- In relation to comorbidities we noticed a higher prevalence of the following comorbidities: cardiovascular disease, neoplasia, COPD, and dementia, especially in the group with more deceased patients;

- During ICU stay, it may be noticed that there was a higher prevalence of mechanical ventilation, vasopressor use, dialysis and tracheostomy in the group that presented more deaths;

- The SAPS3 was higher in patients who died at ICU admission;

- Lymphopenia, elevated D-dimer and the duration in the ICU pre-TQT were higher in the group with more deaths.

The univariate analysis (Table 2$)$ shows the following factors as predictors of survival: myalgia $(p=$ $0.001)$, cardiovascular disease - CVD - $(p=0.002)$, COPD $(p=0.003)$, dementia $(p=0.000)$, the need for mechanical ventilation $(p=0.000)$, dialysis $(0.000)$, vasopressors use $(0.000)$, SAPS3 $(0.000)$, lymphopenia $(p=0.004)$, elevated $D$-dimer $(P=0.011)$, time in ICU before tracheostomy $(p=0.002)$, and performing a tracheostomy $(p=0.000)$. 
Table 2

- Multivariate and Univariate model predictor of mortality

\begin{tabular}{|c|c|c|c|c|}
\hline & Univariate Model & Mu & ivariate Model & \\
\hline Variables & HR (IC95\%) & $\mathrm{p}$ value & HR (IC95\%) & $\mathrm{p}$ value \\
\hline Age & $1,05(1,03-1,07)$ & $<0,001$ & $1,05(1,03-1,07)$ & 0,003 \\
\hline Symptoms of pre-hospitalization & $0,99(0,97-1,01)$ & 0,411 & - & - \\
\hline Myalgia & $2,1(1,1-4,1)$ & 0,032 & & \\
\hline Coronary Insufficiency & $1,5(0,82-2,78)$ & 0,184 & & \\
\hline Heart Insufficiency & $1,56(078-3,08)$ & 0,207 & & \\
\hline Neoplasia & $2,2(1,23-4,04)$ & 0,009 & & \\
\hline DOPC & $2,12(1,1-3,9)$ & 0,017 & & \\
\hline Dementia & $1,9(1,1-3,3)$ & 0,016 & & \\
\hline Invasive Ventilation & $1,06(0,6-1,86)$ & 0,850 & & \\
\hline Vasopressor drugs in ICU & $0,49(0,27-0,89)$ & 0,018 & $0,40(0,21-0,75)$ & 0,001 \\
\hline \multicolumn{5}{|l|}{ Dialysis } \\
\hline Tracheostomy & $1,5(0,84-2,6)$ & 0,169 & $2,6(1,4-4,8)$ & 0,002 \\
\hline Leucocytes $10^{3}$ & $1,0(0,99-1,00)$ & 0,055 & & \\
\hline D-dimer & $1,0(0,99-1,00)$ & 0,154 & & \\
\hline Time in ICU before Tracheostomy & $1,0(0,98-1,02)$ & 0,977 & & \\
\hline
\end{tabular}

According to multivariate analysis (Table 3 ), the independent predictors of mortality were: advanced age $(p=0.003)$; the non-use of vasopressor in the ICU was protective factor $(p=0.001)$; tracheostomy performed in ICU was a mortality predictor $(p=0.002)$, as shown in (Table 2 and 3 ). 
Table 3

- Variate analysis predictor of mortality

\begin{tabular}{|lllll|}
\hline Variables analysis & & & & \\
\hline Age & $1,05(1,03-1,07)$ & $<0,001$ & $1,05(1,03-1,07)$ & 0,003 \\
\hline Symptoms before hospitalization & $0,99(0,97-1,01)$ & 0,411 & - & - \\
\hline Myalgia & $2,1(1,1-4,1)$ & 0,032 & & \\
\hline Coronary insufficiency & $1,5(0,82-2,78)$ & 0,184 & & \\
\hline Cardiac insufficiency & $1,56(078-3,08)$ & 0,207 & & \\
\hline Neoplasia & $2,2(1,23-4,04)$ & 0,009 & & \\
\hline DOPC & $2,12(1,1-3,9)$ & 0,017 & & \\
\hline Dementia & $1,9(1,1-3,3)$ & 0,016 & & \\
\hline Invasive ventilation & $1,06(0,6-1,86)$ & 0,850 & & \\
\hline Vasopressor 2 & $0,49(0,27-0,89)$ & 0,018 & $0,40(0,21-0,75)$ & 0,002 \\
\hline Dialysis & & & & \\
\hline Tracheostomy & $1,5(0,84-2,6)$ & 0,169 & $2,6(1,4-4,8)$ & \\
\hline Lymphocytes & $1,0(0,99-1,00)$ & 0,055 & & \\
\hline D-dimer & $1,0(0,99-1,00)$ & 0,154 & & \\
\hline Time before tracheostomy in ICU & $1,0(0,98-1,02)$ & 0,977 & & \\
\hline
\end{tabular}

\section{Discussion}

The COVID-19 pandemic has pushed health care systems globally to the limit with the unprecedented task of managing large volumes of critically ill patients. This pandemic has affected numerous communities, and reports of overburdened hospitals, specifically critical care units, have become commonplace $4,7,8$. High quality supportive care remains the foundation for ensuring that people with COVID-19 who are critically ill have the best chance of surviving. Such care in pre-pandemic times relied on sufficient expert staffing, specialized equipment, and appropriate environments of care to reliably implement a myriad of processes that are associated with better outcomes ${ }^{15,17}$. Patients with COVID-19 treated in the ICU during periods of high ICU load or demand fared worse than those treated during times of low COVID-19 ICU load or demand. Being elderly and requiring mechanical ventilation had a stronger association with hazard of death, but ICU strain had a clear association with mortality 25 .

The spectrum of disease described in our study is similar to those from the Centers for Disease Control and Prevention's COVID-19-Associated Hospitalization Surveillance Network, the New York City area, and 
China. 21,24 .

We noticed the shorter duration of symptoms during pre-hospitalization was related to worst survival ( $p<$ 0.001), as shown on univariate analysis. The shorter the symptoms, the worse the prognosis and faster the progression to severe presentation.

COVID-19 infection, caused by SARS-CoV-2, has led to a global pandemic. The clinical and pathological features of acute infection have been extensively published, with a wide spectrum of disease seen, from asymptomatic infection to mild self-limiting symptoms to acute respiratory failure requiring invasive mechanical ventilation (MV) ${ }^{26}$. The most common clinical finding is fever, cough and fatigue with some laboratory findings such as increased serum ferritin, D dimers and C reactive protein (CRP) ${ }^{27}$. Some studies reported that risk factors associated with development of acute respiratory distress syndrome and death included older age, neutrophilia, organ dysfunction, coagulopathy, and elevated D-dimer levels 45 .

Previous ICU studies found mortality rates of 62\% (China) and 67\% (USA), but these figures had not accounted for many who were still in the ICU 41,42. However, these numbers may reflect the pandemics beginning, a time when there was not much knowledge about the virus and disease outcome. We found a lower mortality rate (25.4\%), maybe related to the better understanding of the infection.

It affects more older adults and there is also a high fatality rate in this subset of patients. Acute respiratory distress syndrome (ARDS) is the primary cause of death in COVID-19 28 and a recent scope review found that for COVID-19, < $5 \%$ of patients were reported as experiencing bacterial/fungal coinfection at admission, but development of secondary infections during ICU admission is common 29,30 .

As seen in our study, older ages were correlated with increased mortality on univariate $(p<0.001)$ and multivariate $(p=0.003)$ analysis as well. We found an $34 \%(n=68)$ mortality rate, although some authors reported mortality as high as $49 \%$ in patients with critical illness ${ }^{35}$. Regarding gender, our study found $66.3 \%$ male and $33.7 \%$ patients admitted to ICU, showing on this sample a prevalence of men entering ICU. A systematic review including 18.246 patients concluded there was no significant difference between the number of male (50.5\%) and female (49.5\%) patients. Individuals of all age groups were included. On the other hand, another study with 4.203 patients, 2.797 were male (66.5\%) and 1.406 were female (33.5\%).

Early reports have suggested an incubation period of two to 14 days, with clinical presentations ranging from mild infection to severe disease to fatal illness $9,10,11$. The most commonly reported symptoms are cough, fever, and dyspnea 12,13,14,15. Myalgia and gastrointestinal symptoms, including diarrhea and nausea or vomiting, are also common. ${ }^{8}$ In the present study, myalgia was found in $25 \%$ of the patients, and was a survival predictor on univariate analysis $(p<0.001)$. 
The need for mechanical ventilation $(p=0.000)$ and longer ICU stay $(p=0.002)$, were also correlated to worse prognosis on univariate analysis. According to other authors, $97 \%$ of patients on invasive mechanical ventilation died in a multicenter study conducted early in the Wuhan outbreak, mortality is affected by local practices, and larger studies are awaited ${ }^{43}$. The same study reported that $53 \%$ of deaths were related to respiratory failure ${ }^{43}$.

Recent reports $12,15,16,17$ suggest that approximately $14-29 \%$ of hospitalized patients with COVID-19 pneumonia require intensive care, primarily for respiratory support in the setting of hypoxic respiratory failure, with acute respiratory distress syndrome (ARDS) developing in $33 \%$ of hospitalized patients at a median time from symptom onset of eight days ${ }^{9}$. In these reports ${ }^{12,13}$ critically ill patients were older, more likely to be male, and to have underlying comorbidities. The mortality rate ranged from $8.7-21 \%$ among those patients admitted with pneumonia ${ }^{12,14,15,16}$. Our findings support the observations of earlier studies, which found a high percentage of hospitalized patients of advanced age with preexisting conditions, hypertension being the most common $18,19,20$.

COVID-19 rapidly spread throughout the state of São Paulo and has disproportionately affected the population, who have high rates of comorbid conditions and mean BMI of 30 . The obese patients had a high incidence of unfavorable outcome, as reported previously by others authors. In the present study, obesity was present in $27.9 \%$ in the deceased group. Although it is a considerable number of patients, it was not important on univariate analysis $(p=0.748)$.

In the initial reports from Wuhan, China, during the early stages of the pandemic, shortness of breath was reported in 54\% of patients and was associated with composite end point of admission to an ICU, use of mechanical ventilation, and death ${ }^{19}$. A similar prevalence of dyspnea was reported in 21 critically ill patients in Washington State and in the COVID-19-Associated Hospitalization Surveillance Network database ${ }^{21}$. In our series, dyspnea at presentation was associated with hospitalization and the need for ICU management - it was the most prevalent symptom, especially for those who were not discharged $(n=$ $55 / 80.9 \%)$.

Some authors found that the prevalence of dyspnea in the ICU group was $67.2 \%$, compared with $10.2 \%$ in the non-ICU group ${ }^{31}$. Although dyspnea by definition may be indicative of lung involvement and therefore more severe disease, there have been reports of 'silent hypoxia', where oxygen saturations can fall and precipitate acute respiratory failure in the absence of dyspnea and other symptoms of respiratory distress 31,32 .

However, symptoms of fever (65\%), cough (60\%) and myalgia (25.6\%) at presentation were more common among patients in the ICU on univariable analysis, especially myalgia as predictor of survival ( $p$ $=0.001$ ). According to Jail et col, dyspnea was the only symptom significantly associated with both severe disease (pOR 3.70, 95\% Cl 1.83-7.46) and ICU admission (pOR 6.55, 95\% Cl 4.28-10.0), being more strongly associated with the latter ${ }^{31}$. 
A recent systematic review and meta-analysis showed that COPD, CVD and hypertension were the comorbidities significantly predictive for both severe disease and ICU admission. The pORs for severe disease were as follows: COPD $(6.42,95 \% \mathrm{Cl} 2.44-16.9)$, CVD $(2.70,95 \% \mathrm{Cl} 1.52-4.80)$ and hypertension (1.97, 95\% $\mathrm{Cl} 1.40-2.77)$. COPD, CVD and hypertension were more strongly associated with ICU admission, compared with severe disease, with pORs of 17.8 (95\% Cl 6.56-48.2), 4.44 (95\% Cl 2.647.47), and 3.65 (95\% Cl 2.22-5.99), respectively ${ }^{31}$. Those findings corroborate our data, in which COPD $(p=0.003)$ and cardiovascular disease $(p=0.002)$ patients, had higher admission to ICU, and worse prognosis as well. According to Yan et al., COPD was an extremely strong predictor for both severe disease and ICU admission ${ }^{32}$. COPD has been identified as an independent risk factor associated with COVID-19 patients with OR of $5.97(P<0.001)^{36}$. Patients with CVD and hypertension were 4.4 and 3.7 times more likely to have ICU admission, respectively, compared to patients without these comorbidities $^{31,32}$.

The cardiovascular system's complications inducted by SARS-CoV-2 includes: acute myocardial damage, myocarditis, myocardial infarction, heart failure, rhythm disorders, and thromboembolism. Also, in the treatment of COVID-19, interaction with cardiovascular drugs must be considered ${ }^{34}$. A study, which included more than 44,000 COVID-19 patients with diseases of the cardiovascular system, showed a fivefold increase in mortality compared to initially healthy patients ( $10.5 \%$ and $2.3 \%$, respectively) ${ }^{35}$.

A substantial proportion of our patients presenting with gastrointestinal (GI) symptoms - such as diarrhea (18.5\%) - required hospitalization, similar to the data reported in the COVID-19 Associated Hospitalization Surveillance Network ${ }^{22}$. A systematic review of GI symptoms in COVID-19 showed an overall prevalence of diarrhea between $5-10 \%$, although rates varied extensively between studies. Larger cohort studies report prevalence rates between $20-30 \%{ }^{37}$.

Another systematic review including 18.246 patients concluded there was no significant difference between the number of male (50.5\%) and female (49.5\%) patients. Individuals of all age groups were included ${ }^{37}$. The prevalence of GI symptoms was similar among men and women $(52.1 \%$ and $49.5 \%$, respectively). Diarrhea was the most common GI symptom, affecting $11.5 \%$ of the patients, followed by nausea and vomiting (6.3\%) and abdominal pain (2.3\%). With regard to clinical severity, $17.5 \%$ of the patients were classified as severely ill, whereas $9.8 \%$ of them were considered to have a non-severe disease ${ }^{37}$.

Reports suggest that non-invasive ventilation (NIV) and high-flow nasal cannula (HFNC) were used in between one-third and two-thirds of critically ill patients with COVID-19 in China. Minimal data exist to confirm or refute safety concerns regarding the risk of aerossol generation by these devices ${ }^{38}$. Epidemiological data suggest that NIV was associated with nosocomial transmission of SARS; however, human laboratory data suggest that NIV does not generate aerosols. Suggestions that HFNC might be safe are questionable: studies that might be taken to support the safety of HFNC were not designed to show whether or not HFNC is aerosol generating and did not examine the spread of viruses ${ }^{39}$. Those 
data were worrying in the beginning of the pandemics. Our data shows that 174 patients used nasal catheter (NC), 14 HFNC and 71 non-rebreathing mask (NRM) when entering ICU. We did not find any relation to survival according to these factors.

Liang et al. developed and validated a clinical risk score and a web-based risk calculator to predict the development of critical illness among hospitalized COVID-19 infected patients ${ }^{38}$. The ten variables required for calculation of the risk of developing critical illness are generally readily available at hospital admission. Chest radiography abnormality, age, hemoptysis, dyspnea, unconsciousness, number of comorbidities, cancer history, neutrophil-to-lymphocyte ratio, lactate dehydrogenase, and direct bilirubin were included in the COVID risk score. Previous studies have found several of these variables to be risk factors for severe illness related to COVID-19. Although, potential limitations of this study include a modest sample size for constructing the risk score and a relatively small sample for validation. Besides, the data for score development and validation are entirely from China. According to our laboratory findings, lymphopenia $(p=0.004)$, elevated D-dimer $(p=0.011)$ and SAPS3 level, were relevant variables on univariate analysis. The study in 710 patients by Liang et al, showed that radiological abnormalities, number of comorbidities and DHL level, were related to survival im multivariate analysis ${ }^{45}$.

The need for vasopressors drugs might be due one or the combination of such factors: muscle blockers, septic shock, myocarditis or others myocardial disfunctions. The scenario with such findings denotes severe ill patients. We found the need for vasopressors had an impact on survival on multivariate analysis $(p=0.000)$.

Tracheostomy is a common procedure in critically ill patients who require an extended period of time on MV. Use of tracheostomy can facilitate weaning from MV and potentially increase the availability of intensive care unit (ICU) beds. On our analysis, $11 \%$ (22/200) of the patients who was discharged from hospital tracheostomy was performed in ICU. On the other hand, 30.9\% (21/68) of the deceased group underwent tracheostomy, showing higher incidence of such procedure on the worse patients group. According to our data and previous publications, we could infer that tracheostomy did not impact on the natural history of these patients, although those who underwent the procedure had worse prognosis $(p=$ 0.000). On the multivariate analysis, the patients who had tracheostomy had an impact on survival as well $(p=0.002)$. Maybe, we performed tracheostomy in patients in worse conditions for the procedure, advanced age, those who had less conditions for MV weaning, or with more comorbidities. As far as we know, there are no guidelines for COVID-19 patients in MV who should undergo or not to tracheostomy.

\section{Conclusions}

In conclusion, age, the need for vasopressors medications patients who underwent tracheostomy and underlying comorbidities, such as systemic coronary disease, heart failure, neoplasia, COPD, were found to be significantly associated with COVID-19 severity. These pre-existing conditions could increase the susceptibility of such individuals to COVID-19. Recognizing these risk factors could help clinicians reduce mortality by identifying patients with poor prognosis at an early stage. Lymphopenia and elevated D- 
dimer were also related to bad prognosis and worse disease course. Longer time in ICU in our cohort was a bad prognosis marker as well.

The spectrum of disease described in our study is similar to those from the Centers for Disease Control and Prevention's COVID-19-Associated Hospitalization Surveillance Network, the New York City area, and China, as we confirmed the shorter the symptoms, the worse the prognosis.

\section{Declarations}

Ethical Approval and Consent to participate: The institutional review board approved this study $\mathrm{n}^{\circ}$ \#4.849.542: Hospital Alemão Oswaldo Cruz

Consent for publication: "Not applicable" this section

Availability of supporting data: The datasets generated during and/or analysed during the current study are available from the corresponding author on reasonable request.

All data generated or analysed during this study are included in this published article (and its supplementary information files).

Competing interests: The authors declare no conflict of interest in this article.

Funding: This research did not receive any specific grant from funding agencies in the public, commercial, or not-for-profit sectors.

Authors' contributions: All authors declare to contribute in this article.

Acknowledgements: "Not applicable" this section

Conflict of interest: The authors declare no conflict of interest in this article.

\section{References}

1. Lu R, Zhao X, Li J, Niu P, Yang B, Wu H, et al. Genomic characterization and epidemiology of 2019 novel coronavirus: implications for virus origins and receptor binding. Lancet. 2020;395:565-74.

2. Gorbalenya AE, Baker SC, Baric RS, de Groot RJ, Drosten C, Gulyaeva AA, et al. Severe acute respiratory syndrome-related coronavirus: the species and its viruses -a statement of the coronavirus study group. BioRxiv. 2020;20200207:937862.

3. Coronavirus COVID-19 Global Cases by the Center for Systems Science and Engineering (CSSE) at Johns Hopkins University. Available at https://coronavirus.jhu.edu/map.html. Accessed April 24, 2021.

4. Ministry of Health of Brazil. Panel of coronavirus. 2020. (https://covid.saude.gov.br/. Download the CSV file). 
5. Gralinski LE, Menachery VD. Return of the coronavirus: 2019- nCoV. Viruses. 2020;12:135. https://doi.org/10.3390/v12020135.

6. Lurie N, Saville M, Hatchett R, Halton J. Developing Covid-19 vaccines at pandemic speed. N Engl J Med. 2020;382:1969-73.

7. Adhikari SP, Meng S, Wu YJ, Mao YP, Ye RX, Wang QZ, Sun C, Sylvia S, Rozelle S, Raat H, Zhou H. Epidemiology, causes, clinical manifestation and diagnosis, prevention and control of coronavirus disease (COVID-19) during the early outbreak period: a scoping review, Infect Dis Poverty 9 (2020) 29, https:// doi.org/10.1186/s40249-020-00646-x.

8. Amin Gasmi M, Peana L, Pivina S, Srinath AG, Benahmed Y, Semenova A, Menzel. Maryam Dadar, Geir Bjørklund. Interrelations between COVID-19 and other disorders. Clin Immunol. 2021;224:21. https://doi.org/10.1016/j.clim.2020.108651.

9. Centers for Disease Control and Prevention Coronavirus disease 2019 (COVID-19). Accessed April 7. 2020. https://www.cdc.gov/coronavirus/2019-ncov/cases-updates/cases-in-us.html.

10. Wu Z, McGoogan JM. Characteristics of and important lessons from the coronavirus disease 2019 (COVID-19) outbreak in China: summary of a report of 72314 cases from the Chinese Center for Disease Control and Prevention. JAMA. 2020;323(13):1239-42. doi:10.1001/jama.2020.2648 [PubMed] [CrossRef] [Google Scholar].

11. Guan WJ, Ni ZY, Hu Y, et al. China Medical Treatment Expert Group for COVID-19. Clinical characteristics of coronavirus disease 2019 in China. N Engl J Med. 2020;382(18):1708-20. doi:10.1056/NEJMoa2002032 [PMC free article] [PubMed] [CrossRef] [Google Scholar].

12. Richardson S, Hirsch JS, Narasimhan M, et al; Northwell, COVID-19 Research Consortium. Presenting characteristics, comorbidities, and outcomes among 5700 patients hospitalized with COVID-19 in the New York City area. JAMA. 2020;323(20):2052-9. doi:10.1001/jama.2020.6775 [PMC free article] [PubMed] [CrossRef] [Google Scholar].

13. Arentz M, Yim E, Klaff L, et al. Characteristics and outcomes of 21 critically ill patients with COVID-19 in Washington State. JAMA. 2020;323(16):1612-4. doi:10.1001/jama.2020.4326 [PMC free article] [PubMed] [CrossRef] [Google Scholar].

14. Garg S, Kim L, Whitaker M, et al. Hospitalization rates and characteristics of patients hospitalized with laboratory-confirmed coronavirus disease 2019: COVID-NET, 14 states, March 1-30, 2020. MMWR Morb Mortal Wkly Rep. 2020;69(15):458-64. doi:10.15585/mmwr.mm6915e3 [PMC free article] [PubMed] [CrossRef] [Google Scholar].

15. Rodriguez-Morales AJ, Cardona-Ospina JA, Gutiérrez-Ocampo E, et al. Latin American Network of Coronavirus Disease 2019-COVID-19 Research (LANCOVID-19). Clinical, laboratory and imaging features of COVID-19: a systematic review and meta-analysis. Travel Med Infect Dis. 2020;34:101623. doi:10.1016/j.tmaid.2020.101623 [PMC free article] [PubMed] [CrossRef] [Google Scholar].

16. Myers LC, Parodi SM, Escobar GJ, Liu VX. Characteristics of hospitalized adults with ChOVID-19 in an integrated health care system in California. JAMA Published online April 24, 2020. 
doi:10.1001/jama.2020.7202 [PMC free article] [PubMed] [CrossRef] [Google Scholar].

17. Centers for Disease Control and Prevention Severe outcomes among patients with coronavirus disease 2019 (COVID-19). United States, February 12-March 16, 2020. MMWR Morb Mortal Wkly Rep. 2020;69(12):343-6. doi:10.15585/mmwr.mm6912e2 [PMC free article] [PubMed] [CrossRef] [Google Scholar).

18. Richardson S, Hirsch JS, Narasimhan M, et al, Northwell COVID-19 Research Consortium. Presenting characteristics, comorbidities, and outcomes among 5700 patients hospitalized with COVID-19 in the New York City area. JAMA. 2020;323(20):2052-9. doi:10.1001/jama.2020.6775.

19. Garg S, Kim L, Whitaker M, et al. Hospitalization rates and characteristics of patients hospitalized with laboratory-confirmed coronavirus disease 2019: COVID-NET, 14 states, March 1-30, 2020. MMWR Morb Mortal Wkly Rep. 2020;69(15):458-64. doi:10.15585/mmwr.mm6915e3.

20. Rodriguez-Morales AJ, Cardona-Ospina JA, Guti.rrez-Ocampo E, et al. Latin American Network of Coronavirus Disease 2019-COVID-19 Research (LANCOVID-19). Clinical, laboratory and imaging features of COVID-19: a systematic review and meta-analysis. Travel Med Infect Dis. 2020;34:101623. doi:10.1016/j.tmaid.2020.101623.

21. Arentz M, YimE, Klaff L, et al. Characteristics and outcomes of 21 critically ill patients with COVID-19 in Washington State. JAMA. 2020;323(16):1612-4. doi:10.1001/jama.2020.4326.

22. Garg S, Kim L, Whitaker M, et al. Hospitalization rates and characteristics of patients hospitalized with laboratory-confirmed coronavirus disease 2019: COVID-NET, 14 states, March 1-30, 2020. MMWR Morb Mortal Wkly Rep. 2020;69(15):458-64. doi:10.15585/mmwr.mm6915e3.

23. Myers LC, Parodi SM, Escobar GJ, Liu VX. Characteristics of hospitalized adults with COVID-19 in an integrated health care system in California. JAMA Published online April 24, 2020. doi:10.1001/jama.2020.7202.

24. Centers for Disease Control and Prevention. Severe outcomes among patients with coronavirus disease 2019 (COVID-19): United States, February 12-March 16, 2020. MMWR Morb Mortal Wkly Rep. 2020;69(12):343-6. doi:10.15585/mmwr.mm6912e2.

25. Bravata DM, Perkins AJ, Myers LJ, et al. Association of intensive care unit patient load and demand with mortality rates in US Department of Veterans Affairs hospitals during the COVID-19 pandemic. JAMA Netw Open. 2021;4(1):e2034266. doi:10.1001/jamanetworkopen.2020.34266.

26. Wu Z, McGoogan JM. Characteristics of and important lessons from the coronavirus disease 2019 (COVID-19) outbreak in China: summary of a report of 72314 cases from the chinese center for disease control and prevention. JAMA. 2020;323:1239-42. http://dx.doi.org/10.1001/jama.2020.2648.

27. Ge H, Wang X, Yuan X, Xiao G, Wang C, Deng T, et al. The epidemiology and clinical information about COVID-19. Eur J Clin Microbiol Infect Dis. 2020;39:1011-9. http://dx.doi.org/10.1007/s10096020-03874-z.

28. Verity R, Okell LC, Dorigatti I, Winskill P, Whittaker C, Imai N, et al. Estimates of the severity of coronavirus disease 2019: a model-based analysis. Lancet Infect Dis. 2020;20:669-77. 
http://dx.doi.org/10.1016/S1473-3099(20)30243-7.

29. Rawson TM, Moore LSP, Zhu N, Ranganathan N, Skolimowska K, Gilchrist M, et al. Bacterial and fungal co-infection in individuals with coronavirus: a rapid review to support COVID-19 antimicrobial prescribing. Clin Infect Dis. 2020. http://dx.doi.org/10.1093/cid/ciaa530. Online ahead of print.

30. Van Berkel M, Kox M, Frenzel T, Pickkers P, Schouten J, Waanders D, et al. Biomarkers for antimicrobial stewardship: a reappraisal in COVID-19 times? Crit Care. 2020;24:600. http://dx.doi.org/10.1186/s13054-020-03291-w.

31. Yuan JM, Jain Y. Predictive symptoms and comorbidities for severe COVID-19 and intensive care unit admission: a systematic review and meta-analysis. Int J Pub Health. https://doi.org/10.1007/s00038-020-01390-7.

32. Yang J, Zheng Y, Gou X, et al. Prevalence of comorbidities and its effects in coronavirus disease 2019 patients: a systematic Predictive symptoms and comorbidities for severe COVID-19 and intensive care unit admission review and meta-analysis. Int $\mathrm{J}$ Infect Dis. 2020a;94:91-5. https://doi.org/10.1016/j.ijid.2020.03.017.

33. Gattinoni L, Chiumello D, Caironi P, et al (2020) COVID-19 pneumonia: different respiratory treatments for different phenotypes? Intensive Care Med. https://doi.org/10.1007/s00134-020-06033-2.

34. Long B, Brady WJ, Koyfman A, Gottlieb M. Cardiovascular complications in COVID-19. Am J Emerg Med. 2020. https://doi.org/10.1016/j. ajem.2020.04.048.

35. Wu Z, McGoogan JM. Characteristics of and Important Lessons From the Coronavirus Disease 2019 (COVID-19) Outbreak in China: Summary of a Report of 72314 Cases From the Chinese Center for Disease Control and Prevention. JAMA. 2020;323:1239-42. https://doi.org/10.1001/jama.2020.2648.

36. Wang B, Li R, Lu Z, Huang Y. Does comorbidity increase the risk of patients with COVID-19: evidence from meta-analysis. Aging. 2020;12:6049-57. https://doi.org/10.18632/aging.103000.

37. Silva FAF, Brito BB, Santos MLC, et al. COVID-19 gastrointestinal manifestations: a systematic review. Rev. Soc. Bras. Med. Trop. 53 • 2020 • https://doi.org/10.1590/0037-8682-0714-2020.

38. Hui DS, Chow BK, Lo T, et al. Exhaled air dispersion during highflow nasal cannula therapy versus CPAP via different masks. Eur Respir J. 2019;53:1802339.

39. Leung $\mathrm{CCH}$, Joynt GM, Gomersall $\mathrm{CD}$, et al. Comparison of highflow nasal cannula versus oxygen face mask for environmental bacterial contamination in critically ill pneumonia patients: a randomized controlled crossover trial. J Hosp Infect. 2019;101:84-7.

40. Wenhua Liang MD, Hengrui Liang MD, Limin Ou, et al. Development and Validation of a Clinical Risk Score to Predict the Occurrence of Critical Illness in Hospitalized Patients With COVID-19.

41. Yang $X, Y u Y, X u$ J, et al. Clinical course and outcomes of critically ill patients with SARS-CoV-2 pneumonia in Wuhan, China: a singlecentered, retrospective, observational study. Lancet Respir Med. 2020;2600(20):30079-5. https://doi.org/10.1016/S2213-. published online Feb 24.

42. Arentz M, Yim E, Klaff L, et al. Characteristics and outcomes of critically ill patients with COVID-19 in Washington state. JAMA 2020; published online March 19. DOI:10.1001/jama.2020.4326. 
43. Ruan Q, Yang K, Wang W, Jiang L, Song J. Clinical predictors of mortality due to COVID-19 based on an analysis of data of 150 patients from Wuhan, China. Intensive Care Med 2020; published online March 3. DOI:10.1007/s00134-020-05991-x.

44. Zhang JJY, Lee KS, Li WA, Leo YS, Young BE. Risk Factors for Severe Disease and Efficacy of Treatment in Patients Infected with COVID-19: A Systematic Review, Meta-Analy Development and Validation of a Clinical Risk Score to Predict the and Meta-Regression Analysis. Clin Infect Dis. 2020;71(16):2199-206.

45. Liang W, Liang MD. Limin H. Ouet al. Occurrence of Critical Illness in Hospitalized Patients With COVID-19. JAMA Intern Med. doi:10.1001/jamainternmed.2020.2033.

\section{Figures}

Figure 1: The longer the hospital stay, the greater the chance of death

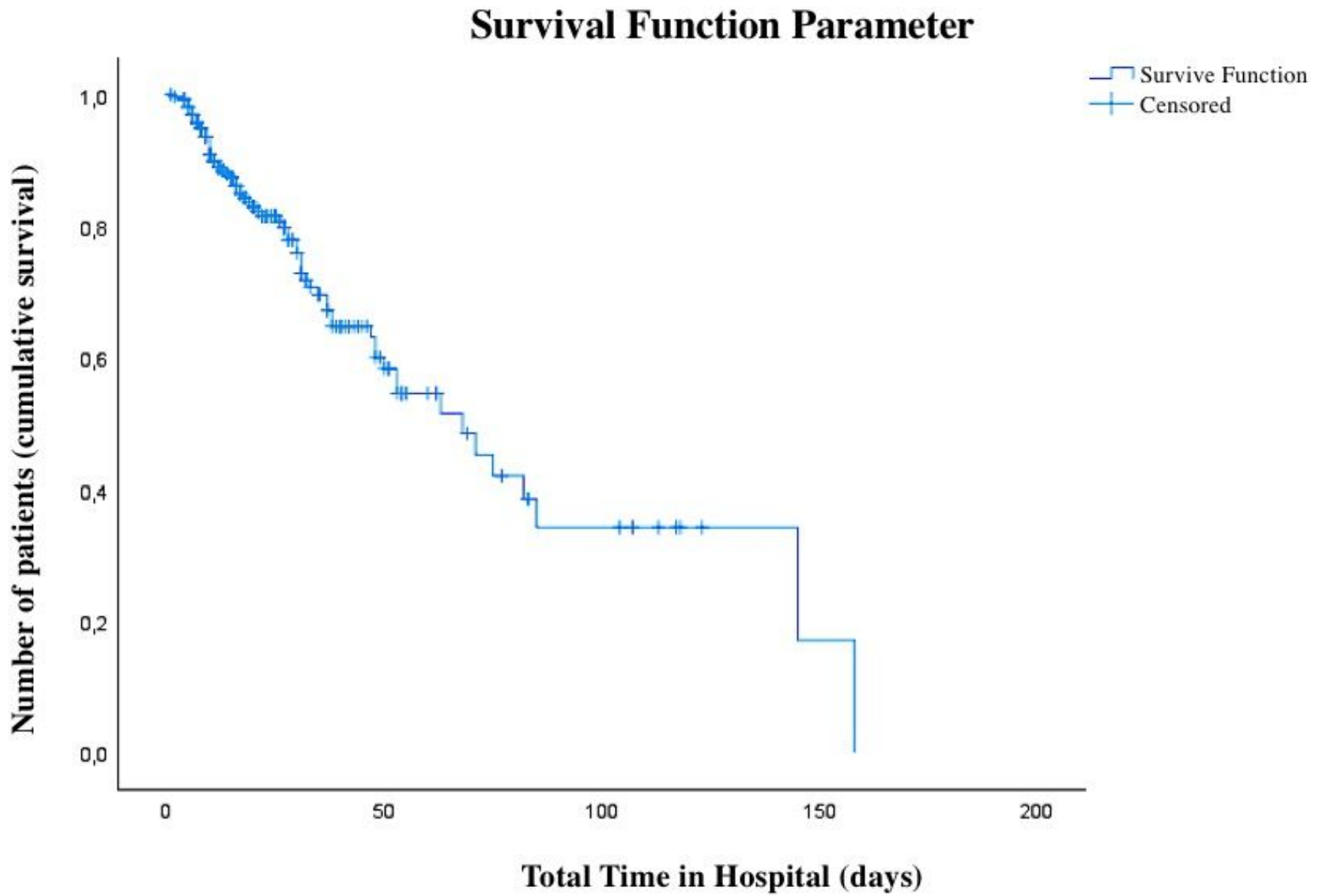

Figure 1

"See image above for figure legend" 
Figure 2: The longer the hospital stay, the greater the chance of death

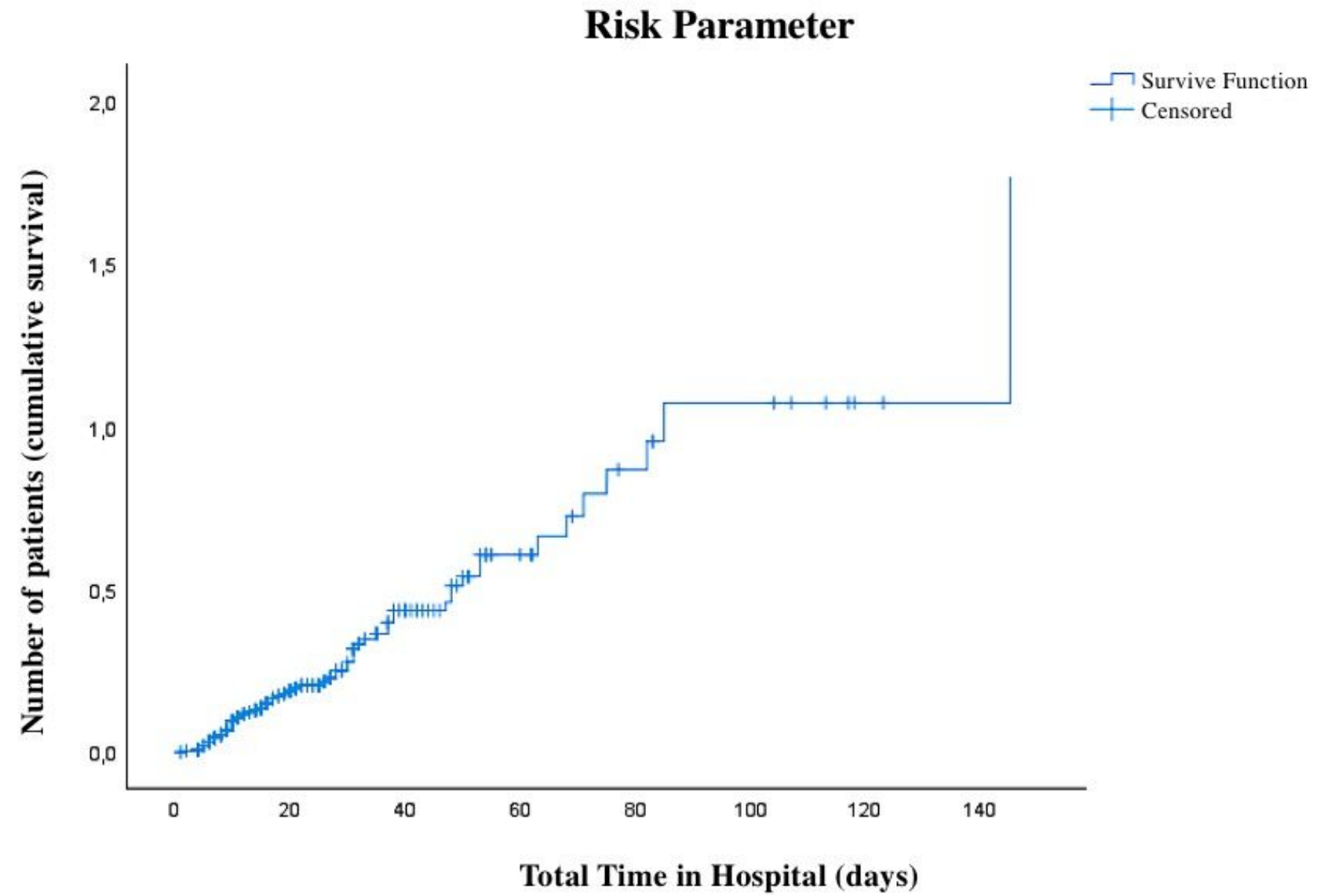

Figure 2

"See image above for figure legend" 